Article

\title{
Antibacterial Character of Cationic Polymers Attached to Carbon-Based Nanomaterials
}

\author{
Daniela Plachá ${ }^{1,2, *}$, Alexandra Muñoz-Bonilla ${ }^{3,4}{ }^{\mathbb{D}}$, Kateřina Škrlová ${ }^{1}$, Coro Echeverria ${ }^{3,4}$, \\ Alberto Chiloeches ${ }^{3,4}$, Martin Petr ${ }^{5}$, Khalid Lafdi ${ }^{6}$ and Marta Fernández-García ${ }^{3,4, * \text { (D) }}$ \\ 1 Nanotechnology Centre, VŠB-Technical University of Ostrava, 17. listopadu 2172/15, \\ 70800 Ostrava-Poruba, Czech Republic; katerina.skrlova@vsb.cz \\ 2 Centre ENET, VŠB-Technical University of Ostrava, 17. listopadu 2172/15, \\ 70800 Ostrava-Poruba, Czech Republic \\ 3 Instituto de Ciencia y Tecnología de Polímeros (ICTP-CSIC), C/Juan de la Cierva 3, 28006 Madrid, Spain; \\ sbonilla@ictp.csic.es (A.M.-B.); cecheverria@ictp.csic.es (C.E.); achiloeches@ictp.csic.es (A.C.) \\ 4 Interdisciplinary Platform for Sustainable Plastics towards a Circular Economy-Spanish National Research \\ Council (SusPlast-CSIC), 28006 Madrid, Spain \\ 5 Regional Centre of Advanced Technologies and Materials, Faculty of Science, Palacký University Olomouc, \\ 17. listopadu 1192/12, 77146 Olomouc, Czech Republic; martin.petr@upol.cz \\ 6 Department of Mechanical and Construction Engineering, Northumbria University, \\ Newcastle upon Tyne NE1 8ST, UK; KHALID.LAFDI@NORTHUMBRIA.AC.UK \\ * Correspondence: daniela.placha@vsb.cz (D.P.); martafg@ictp.csic.es (M.F.-G.); Tel.: +420-597321557 (D.P.); \\ +34-912587530 (M.F.-G.)
}

Received: 5 June 2020; Accepted: 19 June 2020; Published: 22 June 2020

check for updates

\begin{abstract}
The preparation of hybrid polymeric systems based on carbon derivatives with a cationic polymer is described. The polymer used is a copolymer of a quaternizable methacrylic monomer with another dopamine-based monomer capable of anchoring to carbon compounds. Graphene oxide and graphene as well as hybrid polymeric systems were widely characterized by infrared, Raman and photoemission X-ray spectroscopies, electron scanning microscopy, zeta potential and thermal degradation. These allowed confirming the attachment of copolymer onto carbonaceous materials. Besides, the antimicrobial activity of hybrid polymeric systems was tested against Gram positive Staphylococcus aureus and Staphylococcus epidermidis and Gram negative Escherichia coli and Pseudomonas aeruginosa bacteria. The results showed the antibacterial character of these hybrid systems.
\end{abstract}

Keywords: graphene oxide; graphene; antimicrobial; polymer; dopamine; cationic group; functionalizations

\section{Introduction}

In the last recent years, carbon-based nanomaterials have been explored as novel antimicrobial agents, especially for the preparation of antimicrobial and antibiofouling surfaces [1-9]. Some studies have revealed that graphene and its derivatives exhibit excellent antibacterial activity and low mammalian cell toxicity [10], however, the mechanism(s) of this antimicrobial activity still remain controversial [11,12]. Several modes of action have been proposed, e.g., oxidative stress, contact-mediated physical damage and wrapping, although physical properties such as morphology, size, aggregation and surface functionality might affect strongly their antimicrobial activities [13-15]. In spite of this, the low solubility of graphene in both organic and aqueous solvents because of its tendency to aggregate, limits its applicability. For this reason, hydrophilic graphene derivatives have been prevailingly used and tested as antimicrobial agents. Among them, graphene oxide (GO) is the hydrophilic graphene derivative that has been most investigated due to its hydrophilicity 
and its capacity to form homogeneous aqueous dispersions [16-18]. Related to graphene and with the purpose of improving its dispersibility, composite systems have been explored, for instance, by incorporating polymers to form a stable dispersion [19]. The preparation of carbon-based composites not only improves the stability and dispersibility of the systems. but also can tune their properties to develop materials with enhanced antimicrobial activities. Graphene and its derivative materials have relatively high specific surface area with abundant surface functionalities in case of graphene oxide, which have the potential for the preparation of multiple composite antibacterial materials in combination with other antimicrobial agents [20,21]. It has been proved the synergistic or additive effect of graphene derivatives with silver composite materials, leading an enhanced activity at low concentration [22-25]. Similarly, hybrid systems with $\mathrm{ZnO}$ and $\mathrm{TiO}_{2}$ nanoparticles have demonstrated excellent antibacterial activity [26-28]. Polymer-based composites have received special attention due to their versatility and capacity to control their properties. In particular, cationic antimicrobial polymers such as quaternary ammonium polymers, chitosan or polyethyleneimine polymer (PEI) have been widely used in combination with graphene derivatives [29-32]. The general accepted antimicrobial mechanism of cationic polymers is associated with adsorption on the negatively charged bacterial wall through electrostatic interactions, which augments membrane permeability and subsequently disrupts the membrane. In addition to the antimicrobial activity, the cationic polymers provide stability, dispersibility in aqueous media and could also reduce toxicity. There are three main approaches to develop graphene-polymer composites: physical mixing, covalent bonding of the polymer to graphenic structure and through non-covalent interactions, such as van der Waals forces, hydrophobic interactions, and $\pi-\pi$ stacking.

In the present study, we have incorporated a monomer with catechol side chains in a methacrylic cationic polymer, which exhibit excellent antimicrobial activity with the aim to improve the immobilization on graphene derivatives. The copolymer was composed of $N$-(3,4-dihydroxyphenethyl) methacrylamide (DOMA) and 2-(4-methylthiazol-5-yl)ethyl methacrylate (MTA) quaternized with methyl iodide [33]. The randomly distributed DOMA units have the capacity to strongly adhere on graphene and graphene oxide sheets through $\pi-\pi$ stacking interaction that stabilizes the dispersion of the nanocomposite. These adhesive units would also be used to bind different surfaces and create antimicrobial coatings.

\section{Materials and Methods}

\subsection{Materials}

Graphite flakes for graphene oxide (GO) synthesis were supplied by Sigma Aldrich (Praha, Czech Republic). Concentrated sulphuric acid $\left(\mathrm{H}_{2} \mathrm{SO}_{4}, 98 \%\right)$, potassium permanganate $\left(\mathrm{KMnO}_{4}, \geq 99 \%\right)$, hydrogen peroxide $\left(\mathrm{H}_{2} \mathrm{O}_{2}, 30 \%\right)$ and hydrochloric acid $(\mathrm{HCl}, 35-37 \%)$ were procured from VWR International (Stříbrná Skalice, Czech Republic). Ultra-pure water (Milli Q, Merck, Praha, Czech Republic) was used for synthesis as well as washing.

Monomers N-(3,4-dihydroxyphenethyl) methacrylamide (DOMA) and 2-(4-methylthiazol-5-yl) ethyl methacrylate (MTA) were synthetized according to previous work and used for consequent preparation of the statistical copolymer $\mathrm{P}\left(\mathrm{MTA}_{\mathrm{x}}-\mathrm{co}-\mathrm{DOMA} \mathrm{y}\right)$ with monomer molar ratio MTA/DOMA $=90 / 10$ by free radical polymerization $\left(M_{n}=24,600 \mathrm{~g} / \mathrm{mol}\right)$ [33]. The prepared copolymer was then quaternized with iodomethane (MeI, 99\%, supplied by Sigma Aldrich) leading the corresponding cationic copolymer bearing thiazolium groups (named as MD10). This quartenized copolymer was used for functionalization of graphene (GR) and GO.

For microbiological studies: sodium chloride aqueous solution $(\mathrm{NaCl}, 0.9 \%$, BioXtra, suitable for cell cultures) and phosphate buffered saline (PBS, pH 7.4) were purchased from Sigma-Aldrich (St. Louis, MO, USA). BBL ${ }^{\mathrm{TM}}$ Mueller-Hinton broth was supplied by Becton, Dickinson and Company (Madrid, Spain) and was used as a microbial growth medium. The 96 well microplates were obtained from Thermo Scientific (Madrid, Spain). Representative bacterial species, two Gram positive 
Staphylococcus aureus (S. aureus, ATCC 29213) and Staphylococcus epidermidis (S. epidermidis, ATCC 12228) and two Gram negative Escherichia coli (E. coli, ATCC 25922) and Pseudomonas aeruginosa (P. aeruginosa, ATCC 27853) were obtained from Oxoid ${ }^{\mathrm{TM}}$ (Madrid, Spain) and chosen as model bacterial strains in the present study.

\subsection{Synthesis of $G O$ and $G R$}

Graphene oxide (GO) was prepared from graphite according to slightly modified Hummers method [34]. Briefly, graphite flakes $(10 \mathrm{~g})$ were dispersed firstly in concentrated sulfuric acid solution $(250 \mathrm{~mL})$ in an ice bath, then $\mathrm{KMnO}_{4}(30 \mathrm{~g})$ was slowly added and the mixture was kept stirring for $3 \mathrm{~h}$. Subsequently, the mixture was diluted with distilled water $(2 \mathrm{~L})$ followed by adding $30 \%$ hydrogen peroxide $(50 \mathrm{~mL})$ drop-by-drop. This pre-oxidized product was further oxidized by repeating the previous procedure: pre-product was well mixed with $\mathrm{H}_{2} \mathrm{SO}_{4}(250 \mathrm{~mL})$, then $\mathrm{KMnO}_{4}(30 \mathrm{~g})$, distilled water $(2 \mathrm{~L})$ and $30 \%$ hydrogen peroxide $(50 \mathrm{~mL})$ were gradually added. Finally, the product was washed repeatedly with diluted $\mathrm{HCl}(1: 10)$ and consequently with demineralized water until $\mathrm{pH}$ value of this solution was neutral. The solid phase was then separated and dried overnight at $40{ }^{\circ} \mathrm{C}$ to obtain GO. Exfoliated graphite (GR) was prepared by processes of intercalation and exfoliation of graphite flakes with an average diameter of $500 \mathrm{~mm}$ [35]. The intercalated material was subjected to heating in a high temperature reactor at $900{ }^{\circ} \mathrm{C}$. Resulted material was grounded after cooling [35].

\subsection{GO and GR Functionalization}

The functionalization of GO was conducted in aqueous solution. At first, GO (approx. $70 \mathrm{mg}$ ) was properly dispersed in distilled water $(30 \mathrm{~mL})$ in an ultrasonic bath for two hours. After sonication, there were no visible GO particles in the mixture. Simultaneously, MD10 polymer (70 mg) was dissolved in distilled water $(30 \mathrm{~mL})$. Then, the aqueous suspension of GO was quantitatively added to the polymer solution to prepare a mixture containing GO/polymer ratio 1:1. The mixture was well magnetically stirred for 2 weeks at room temperature. The sample was denoted as GO_MD10. In the case of GR functionalization, the procedure was exactly the same than with GO but the solvent used was DMF. The sample was denoted as GR_MD10.

After that, both samples were repeatedly washed with distilled water and centrifuged (5810 R centrifuge, Eppendorf, Madrid, Spain) at 12,000 rpm for $30 \mathrm{~min}$ to eliminate all non-attached polymers and the DMF solvent in the case of GR. The non-attached polymers elimination in both samples was checked by analysis of obtained supernatants using UV/VIS spectrometer (NanoDrop ${ }^{\mathrm{TM}} \mathrm{One}^{\mathrm{C}}$ microvolume UV-Vis spectrophotometer, Thermo Fisher Scientific). Finally, the solid phases were dried at $50{ }^{\circ} \mathrm{C}$ until constant weight.

\subsection{Characterization of Hybrid Materials}

A Zetasizer Nano ZS (Malvern Instruments, Malvern, United Kingdom) was used to estimate the charge potential of the prepared materials. Samples were dispersed in distilled water $(10 \mu \mathrm{g} / \mathrm{mL})$ and measured at $25^{\circ} \mathrm{C}$. Each measurement was repeated at least ten times.

Thermogravimetric analysis (TGA) was conducted using a TGA Q500 analyzer (TA Instruments, New Castle, DE, USA) from room temperature to $900{ }^{\circ} \mathrm{C}$ at a heating rate of $10^{\circ} \mathrm{C} / \mathrm{min}$ under an air atmosphere. The instrument was calibrated in temperature and weight by standard methods.

Fourier transform infrared spectroscopy (FTIR) was conducted on a Spectrum Two FT-IR spectrometer (Perkin Elmer, Waltham, MA, USA) in range of $4000-400 \mathrm{~cm}^{-1}$ with resolution of $4 \mathrm{~cm}^{-1}$. Approximately $2 \mathrm{mg}$ of each sample and $200 \mathrm{mg}$ of KBr (FT-IR purity, spectroscopically dry, Sigma Aldrich) were weighted and transferred to an agate mortar, grinded together and $\mathrm{KBr}$ pellets were prepared using a hydraulic press.

Raman spectra of prepared samples were recorded with a Renishaw inVia Reflex Raman system (Renishaw plc, Wotton-under-Edge, UK) using a grating spectrometer with an $1800 \mathrm{~mm}^{-1}$ Peltier-cooled charge-coupled device (CCD) detector, coupled to a confocal microscope operating at an excitation 
wavelength of $532 \mathrm{~nm}$. Samples were prepared by drop-casting of diluted samples solutions on freshly cleaved $\mathrm{SiO}_{2} / \mathrm{Si}$ wafers and dried at room temperature.

The XPS measurements were carried out with the PHI 5000 VersaProbe II XPS system (Physical Electronics, Chanhassen, MN, USA) with monochromatic Al-K $\alpha$ source $(15 \mathrm{kV}, 50 \mathrm{~W})$ and photon energy of $1486.7 \mathrm{eV}$. All the spectra were measured in the vacuum of $1.4 \times 10^{-7} \mathrm{~Pa}$ and at $20.5^{\circ} \mathrm{C}$. The analyzed area on the sample had a spot of $100 \mu \mathrm{m}$ in diameter. The survey spectra were measured with pass energy of $187.850 \mathrm{eV}$ and step of $0.8 \mathrm{eV}$, while for the high resolution spectra were used pass energy of $23.500 \mathrm{eV}$ and step of $0.2 \mathrm{eV}$. Dual beam charge compensation was used for all measurements. The spectra were eValuated with the MultiPak (Ulvac-PHI, Inc., Chanhassen, MN, USA) software. All binding energy (BE) values were referenced to the carbon peak $\mathrm{C} 1 \mathrm{~s}$ at $284.80 \mathrm{eV}$.

The morphology of the samples were characterized by field emission scanning electron microscopy (FE-SEM) using a SU 8000 microscope (Hitachi, Hitachi, Japan) at $5 \mathrm{kV}$ in transmitted electron imaging mode. Diluted aqueous solutions of the samples were pipetted onto carbon Type-A 400-mesh TEM copper grid obtained from Tedpella Inc. (Redding, CA, USA), and then were dried with filter paper.

\subsection{Antimicrobial Activity}

Firstly, the bacteria (Gram-positive Staphylococcus aureus (S. aureus, ATCC ${ }^{\circledR} 29213$ ), staphylococcus coagulase-negative Staphylococcus epidermidis (S. epidermidis, ATCC ${ }^{\circledR}$ 12221) and Gram-negative Escherichia coli (E. coli, ATCC ${ }^{\circledR}$ 25922) and Pseudomonas aeruginosa (P. aeruginosa, ATCC $\left.{ }^{\circledR} 27853\right)$ ), were incubated on Columbia Agar plates with 5\% sheep blood for $24 \mathrm{~h}$ at $37{ }^{\circ} \mathrm{C}$ in a IQ050 incubator (Jouan, Winchester, VA, USA). Subsequently, bacteria suspensions of about $10^{8}$ colony-forming units (CFU) were prepared by adjusting concentration with saline solution to ca. 0.5-0.6 of the McFarland turbidity standard. Suspensions of ca. $2 \times 10^{6} \mathrm{CFU} \mathrm{mL}{ }^{-1}$ were finally obtained by further dilution with Mueller-Hinton broth. The dispersion of the samples in Mueller-Hinton broth $(1 \mathrm{mg} / \mathrm{mL})$ were prepared in glass vials, sonicated and sterilized by UV radiation for $30 \mathrm{~min}$ before experiments. Then, $800 \mu \mathrm{L}$ of bacterial suspension was added to $200 \mu \mathrm{L}$ sample dispersion to reach a final concentration of $500 \mu \mathrm{g} / \mathrm{mL}$. Control experiments with only inoculum were also performed. The vials were incubated with gentle shaking during $24 \mathrm{~h}$ and then, $200 \mu \mathrm{L}$ of each solution (without residue of carbon material) were placed in a 96-well plate. Bacterial growth was reflected by the absorption of optical density (OD) at $550 \mathrm{~nm}$ via a microplate reader (VirClia ${ }^{\circledR}$ Chemiluminescence). The measurements were made at least in triplicate and the antibacterial ratio was calculated as follows:

$$
\text { Antibacterial ratio }=\frac{\text { OD of control }- \text { OD of sample }}{\text { OD of control }} \times 100
$$

\section{Results}

The attachment of polymers to the GO or GR surfaces is eValuated by different techniques. Firstly, FTIR spectra of the carbon-based hybrid materials as well as GO, GR and the copolymer are shown in Figure 1. In the spectra of GO and GR, the presence of oxygenated groups are appreciated. Characteristic vibration and deformation bands at $3410 \mathrm{~cm}^{-1}(\mathrm{O}-\mathrm{H}), 1716(-\mathrm{C}=\mathrm{O}), 1615\left(\mathrm{sp}^{2}\right.$ aromatic $\mathrm{C}-\mathrm{C}), 1164$ ( $\mathrm{sp}^{2}$ aromatic $\mathrm{CH}$ in plane) and $1052 \mathrm{~cm}^{-1}(\mathrm{C}-\mathrm{O}-\mathrm{C})$ were observed in the $\mathrm{GO}$ pattern. Bands with very low intensity at $3441(\mathrm{O}-\mathrm{H}), 1738(-\mathrm{C}=\mathrm{O}), 1385(-\mathrm{C}-\mathrm{O}), 1065$ and $1020(\mathrm{C}-\mathrm{O}-\mathrm{C}) \mathrm{cm}^{-1}$ are also identified in the GR spectrum. In the case of copolymer, characteristic bands at 3420, 3089, 3001 and $2936 \mathrm{~cm}^{-1}$ can be easily assigned to $\mathrm{O}-\mathrm{H}$ bonds, $\mathrm{sp}^{2}$ asymetric vibration of $=\mathrm{CH}_{2},-\mathrm{C}=\mathrm{N}$, sp ${ }^{2}$ aromatic $\mathrm{CH}$ and sp ${ }^{3}$ asymetric $-\mathrm{CH}_{3}$, respectively. The band at ca. $1660 \mathrm{~cm}^{-1}$ is associated to $-\mathrm{C}=\mathrm{O}$ groups of DOMA comonomer, while the band at $1720 \mathrm{~cm}^{-1}$ is asignated to $-\mathrm{C}=\mathrm{O}$ groups of MTA comonomer. The band at $1595 \mathrm{~cm}^{-1}$ corresponds to $-\mathrm{C}=\mathrm{N}^{+}$of the thiazolium groups of MTA units and the strong band at $1150 \mathrm{~cm}^{-1}$ is assignated to $\mathrm{C}-\mathrm{O}$ groups of MTA units. The attachment of the cationic polymer to obtain the hybrid materials is eVident by the presence of carbonyl groups of DOMA and MTA units in each spectrum. 


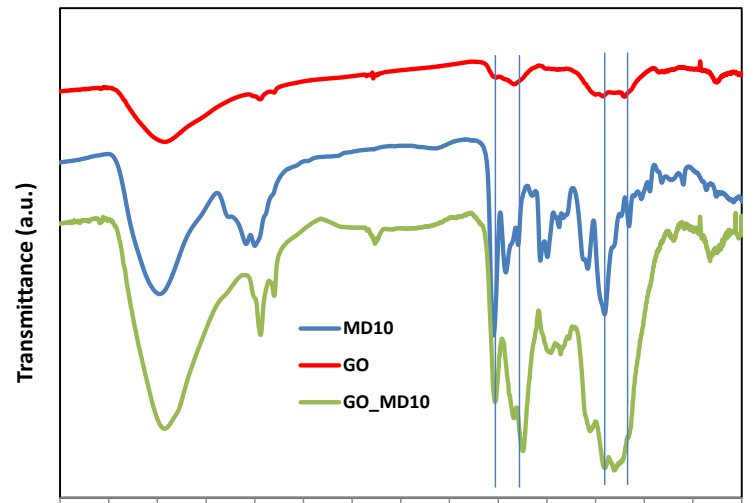

395037003450320029502700245022001950170014501200950700450 Wavenumber $\left(\mathrm{cm}^{-1}\right)$

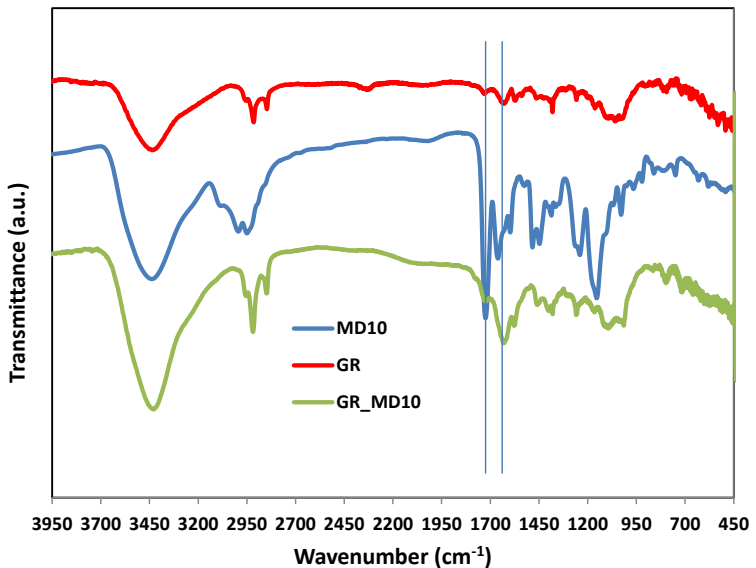

Wavenumber $\left(\mathrm{cm}^{-1}\right)$

Figure 1. FTIR spectra of hybrid polymeric materials, GO, GR and MD10.

Raman spectra of GO, GR and their hybrid materials are presented in Figure 2. The spectrum of polymer was not possible to measure because of its fluorescence emission. The spectrum of GO shows the typical D (defects inherent in the graphite and the edge effect of graphite, A1g mode) and $\mathrm{G}$ (first-order scattering of E2g phonons by sp carbon atoms) bands at 1350 and $1610 \mathrm{~cm}^{-1}$, respectively [36]. There is a broad band in the area around $3000 \mathrm{~cm}^{-1}$ that is assigned to $2 \mathrm{D}, \mathrm{G}+\mathrm{D}$ and 2D' peaks. These bands are characteristics of GO. Meanwhile, the GR spectrum shows that the obtained material is exfoliated graphite. A prominent $\mathrm{G}$ band at $1564 \mathrm{~cm}^{-1}$ is displayed, the intensity of $\mathrm{D}$ band at $1338 \mathrm{~cm}^{-1}$ is very low and the intensity ratio between both bands $\left(\mathrm{I}_{\mathrm{D}} / \mathrm{I}_{\mathrm{G}}\right)$ is 0.05 , which indicates the low presence of defects in the structure [37]. As known, the 2D peak between 2600 and $2800 \mathrm{~cm}^{-1}$ in bulk graphite consists of two components $2 \mathrm{D}_{1}$ and $2 \mathrm{D}_{2}$ [38]. The splitting of this broad Raman band opens up in going from mono- to three-layer graphene and then closes up in going from four layers to highly oriented pyrolytic graphite $[39,40]$. Intensity ratio of $2 D / G$ peak gives idea about the number of layers; its value is 2 for monolayer, 1 for bilayer, and as this value decreases the number of layers increases. In the case of GR and after deconvolution of 2D peak, this ratio is 0.25 , which indicates that GR presents a large number of layers.
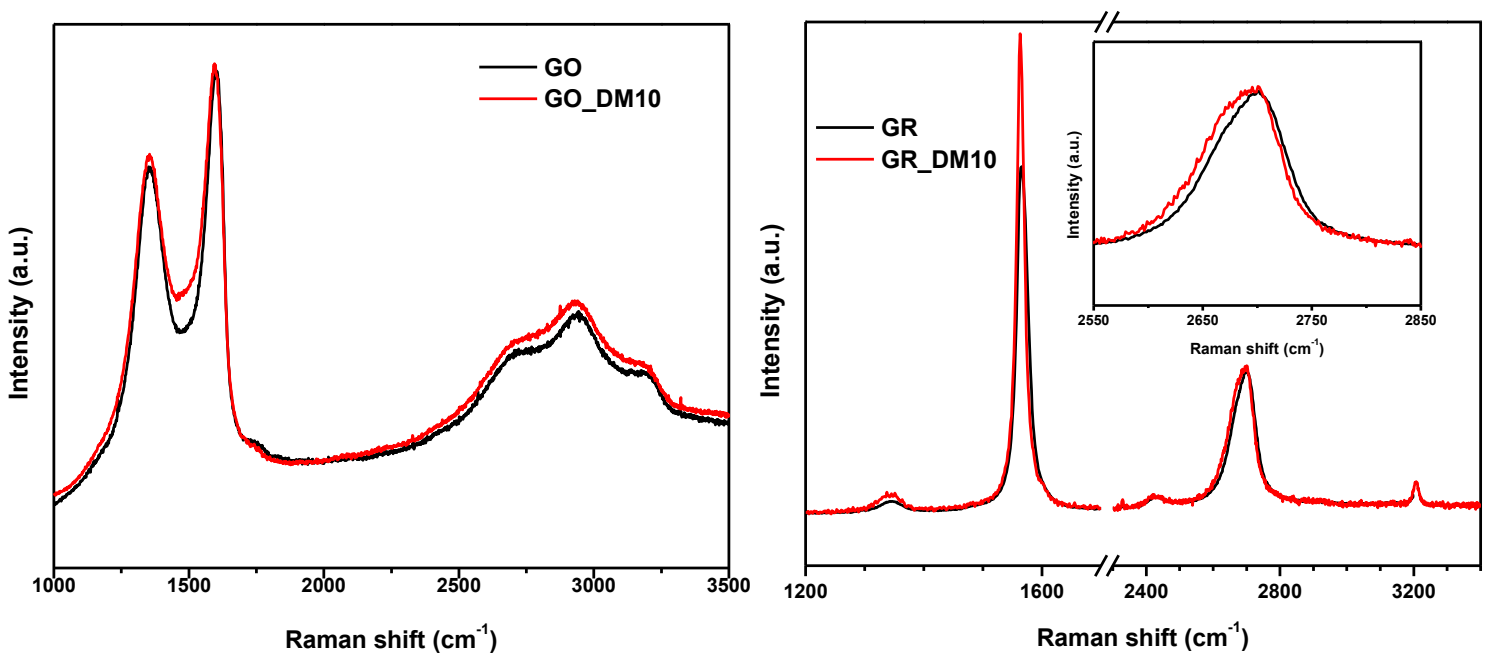

Figure 2. Raman spectra of the hybrid polymeric materials with GO and GR, respectively.

The Raman spectrum of GO-hybrid polymeric material shows minor changes compare to GO. The spectra are nearly identical; there are no shifts in positions of $\mathrm{D}$ and $\mathrm{G}$ bands; however, in a deeper inspection by deconvoluting the spectra a new band at $1540 \mathrm{~cm}^{-1}$ appears when polymer is attached 
(see Figure 3). The G and D bands do not change, so the GO structure is maintained, and the new bands could corresponds to $-\mathrm{C}-\mathrm{O}-\mathrm{C}-$ bond from the ring of DOMA and the graphitic structure of GO.
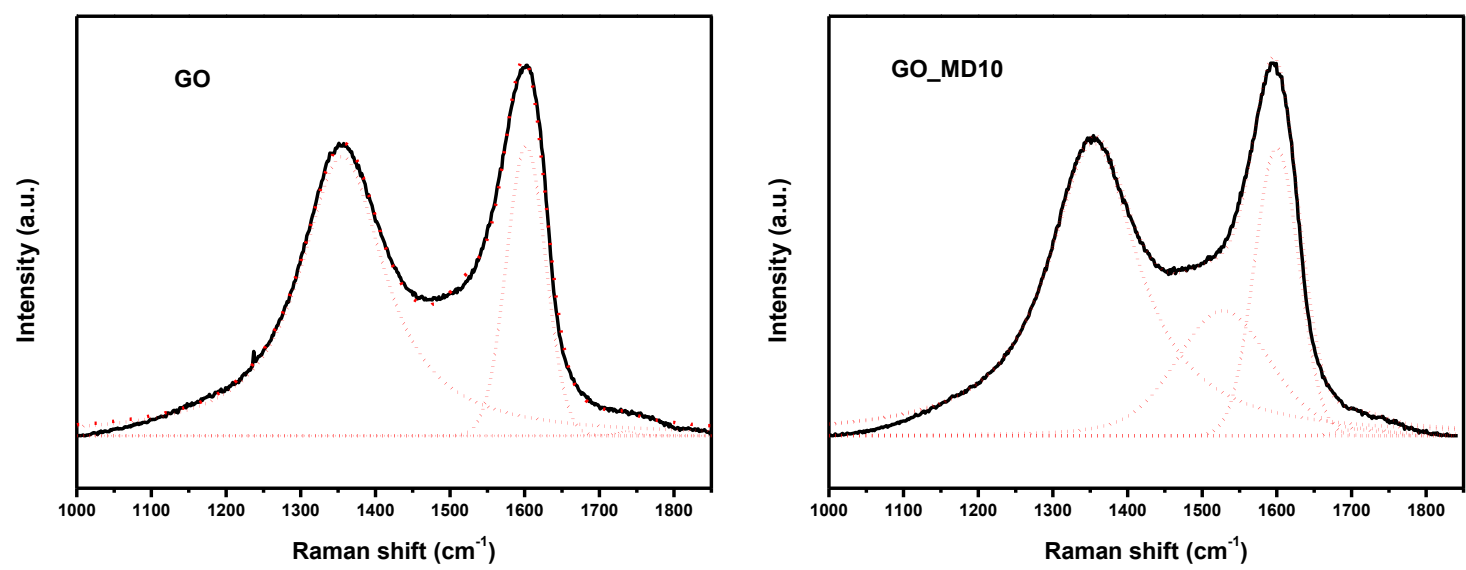

Figure 3. Deconvolution of Raman spectra of GO and GO_MD10 in the range of 1000-1850 $\mathrm{cm}^{-1}$.

There are also some substantial changes in GR derivative. There are changes on the intensity of D, $\mathrm{G}$ and $2 \mathrm{D}$ bands; the ratio of $\mathrm{I}_{\mathrm{D}} / \mathrm{I}_{\mathrm{G}}$ is a slightly higher 0.08 and also the shape of $2 \mathrm{D}$ band has changed (see the insert). These features can correspond to the intercalation of polymer chains between graphitic layers and formation of graphene stacks with less number of layers.

Subsequently, the morphology and structural properties of the prepared GO and GR as well as the hybrid materials are studied using the FESEM images. Figure 4 shows the micrographs of GO, GR and their corresponding hybrid polymeric materials.

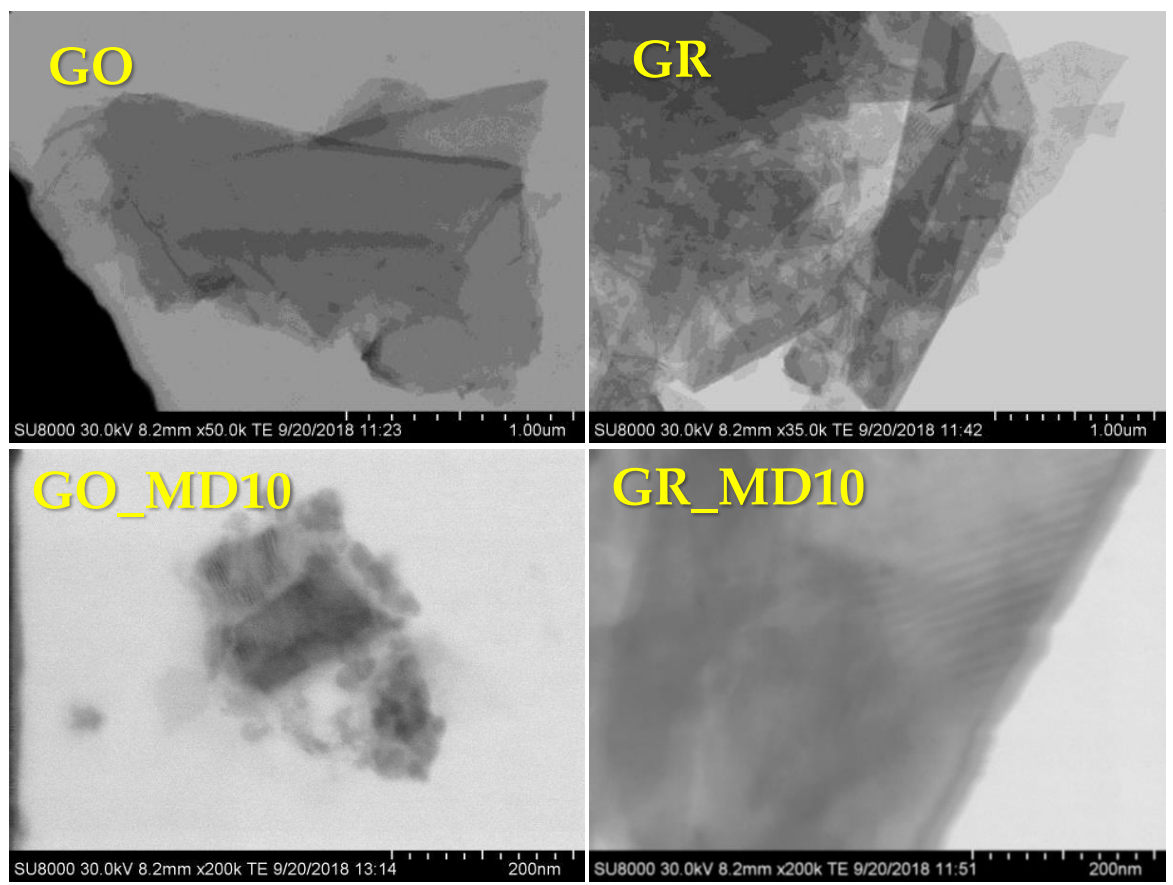

Figure 4. FESEM images of GO and GR and functionalized hybrid materials with MD10.

In all the cases, the suspended materials are constituted in sheets of several microns; the regular shapes of flakes are visible. GO sheets present shaped like a cluster of agglomerating flakes with regular and sharp edges of several microns. GR sheets also agglomerate but present smaller size than GO. Moreover, the functionalization with polymer seems to provoke the delamination of GR layers into smaller stacks. 
Next, the attachment of polymers to carbonaceous materials was also analyzed by thermogravimetry under air atmosphere. Figure 5 a shows thermal stabilities of the hybrid sample GO_MD10, compared to GO and MD10 polymer. The degradation of the cationic polymer occurs in three stages [41], whereas the GO degrades in two steps, in addition to the loss of adsorbed/absorbed water. The first process at $235^{\circ} \mathrm{C}$ is ascribed to the removal of most of functional groups containing oxygen such as labile epoxy, hydroxyl, and carboxylic groups ( $36 \%$ weight loss) from the GO structure, whereas the second decrease in weight, at around $483^{\circ} \mathrm{C}$, is abrupt and can be associated to the complete thermal decomposition of GO [42]. Table 1 summarizes the decomposition temperatures at $5 \%$ weight loss $\left(T_{d 5}\right)$ and the temperatures of the maximum rate of weight loss for each step $\left(T_{d}{ }^{\max 1}, T_{d}{ }^{\max 2}\right.$, $\mathrm{T}_{\mathrm{d}}{ }^{\max 3}$ and $\mathrm{T}_{\mathrm{d}}{ }^{\max 4}$ ) for all the samples. The TGA graph also shows that the GO_MD10 decomposes in several degradation processes. Clearly, the stability of the hybrid sample was in between the stability of GO and the initial polymer, with $\mathrm{T}_{\mathrm{d} 5}$ value of $185^{\circ} \mathrm{C}$. The first degradation process of the GO_MD10 presented a $\mathrm{T}_{\mathrm{d}}{ }^{\max 1}=188^{\circ} \mathrm{C}$, thus at lower temperatures than that of GO and MD10, whereas the rest of the decomposition steps occurred at higher temperatures. This behavior is in agreement with that of other functionalized GO samples, which is associated to the capping of the reactive surface functionalities of GO that are probably sites of decomposition $[43,44]$. Therefore, the TGA analysis confirms the successful attachment of the cationic polymer onto the GO.
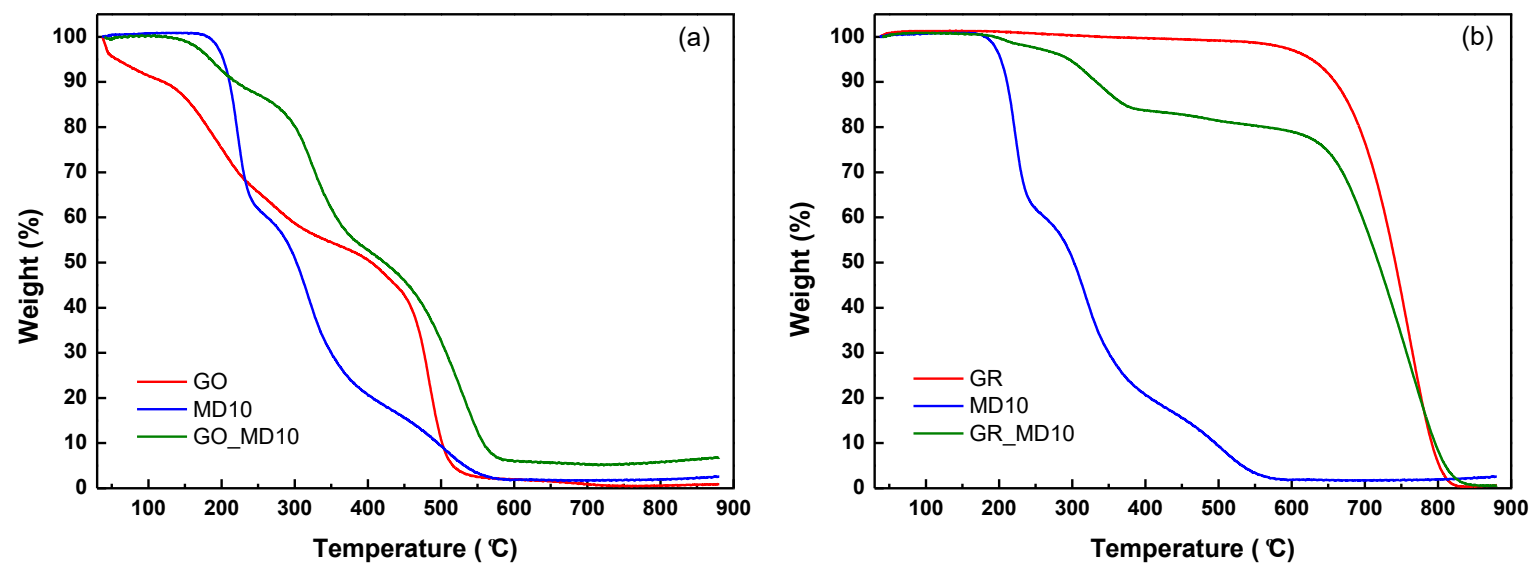

Figure 5. Thermogravimetric (TGA) analysis of (a) graphene oxide hybrid sample GO_MD10 compared to GO and MD10 polymers; and (b) graphene hybrid sample, GR_MD10 compared to, MD10 and GR.

Table 1. Characteristic parameters of the thermal degradation of hybrid materials, the decomposition temperatures at $5 \%$ weight loss $\left(\mathrm{T}_{\mathrm{d} 5}\right)$ and the temperatures of the maximum rate of weight loss for each step $\left(\mathrm{T}_{\mathrm{d}}^{\max 1}, \mathrm{~T}_{\mathrm{d}}^{\max 2}, \mathrm{~T}_{\mathrm{d}}^{\max 3}\right.$ and $\left.\mathrm{T}_{\mathrm{d}}^{\max 4}\right)$.

\begin{tabular}{cccccc}
\hline Material & $\mathbf{T}_{\mathbf{d} 5}\left({ }^{\circ} \mathbf{C}\right)$ & $\mathbf{T}_{\mathbf{d}}{ }^{\max 1}\left({ }^{\circ} \mathbf{C}\right)$ & $\mathbf{T}_{\mathbf{d}}{ }^{\max 2}\left({ }^{\circ} \mathbf{C}\right)$ & $\mathbf{T}_{\mathbf{d}}{ }^{\max 3}\left({ }^{\circ} \mathbf{C}\right)$ & $\mathbf{T}_{\mathbf{d}}{ }^{\max 4}\left({ }^{\circ} \mathbf{C}\right)$ \\
\hline MD10 & 202 & 221 & 316 & 511 & - \\
GO & 158 & 235 & 483 & - & - \\
GO_MD10 & 185 & 188 & 320 & 533 & - \\
GR & 628 & 760 & - & - & - \\
GR_MD10 & 296 & 210 & 347 & 484 & 762 \\
\hline
\end{tabular}

Likewise, the TGA analysis of the graphene-based hybrid sample, GR_MD10, also corroborates the immobilization of the cationic polymer onto the graphene sheets (see Figure $5 b$ and Table 1 ) of around $10 \mathrm{wt} \%$ of polymer. The graphene is stable up to $628^{\circ} \mathrm{C}$ with weight loss of $5 \%$. This high stability of graphene results from the strong $\pi-\pi$ interactions of the structure. On the other hand, the GR_MD10 started to decompose at $296^{\circ} \mathrm{C}$ due to the present of polymer and showed four degradation stages. The first three processes are associated to the polymer immobilized on the graphene, while the last stage at $\mathrm{T}_{\mathrm{d}}{ }^{\max }=762{ }^{\circ} \mathrm{C}$ corresponds to the complete degradation of graphene sheets. 
Moreover, the surface of all materials was analyzed by XPS to confirm the attachment of polymer. Figures 6 and 7 display the C1s profiles of GO and GR and their hybrid materials, respectively. Firstly, $\mathrm{C} 1 \mathrm{~s}$ profile in $\mathrm{GO}$ shows a considerable degree of oxidation with five components that correspond to $\mathrm{C}$ atoms of non-oxygenated $\mathrm{C}=\mathrm{C}\left(\mathrm{sp}^{2}\right)$ of aromatic rings $(284.80 \mathrm{eV})$, the reduced $\mathrm{C}-\mathrm{C}\left(\mathrm{sp}^{3}\right)$ bonds $(286.16 \mathrm{eV})$, and $\mathrm{C}$ atoms in $-\mathrm{C}-\mathrm{O}, \mathrm{C}=\mathrm{O}$ and carboxylate, 286.97, 288.14 and 289.14 eV, respectively. In the C1s spectrum of hybrid GO_MD10 system a higher occurrence of $\mathrm{sp}^{3} \mathrm{C}-\mathrm{C}$ as well as a clear decrease on the amount of $\mathrm{C}-\mathrm{O}$ bond are observed. The N1s spectrum confirmed presence of both $\mathrm{O}=\mathrm{C}-\mathrm{N}$, and quarternary $\mathrm{C}-\mathrm{N}$ bond, indicating the attachment of polymers to the carbonaceous surface.
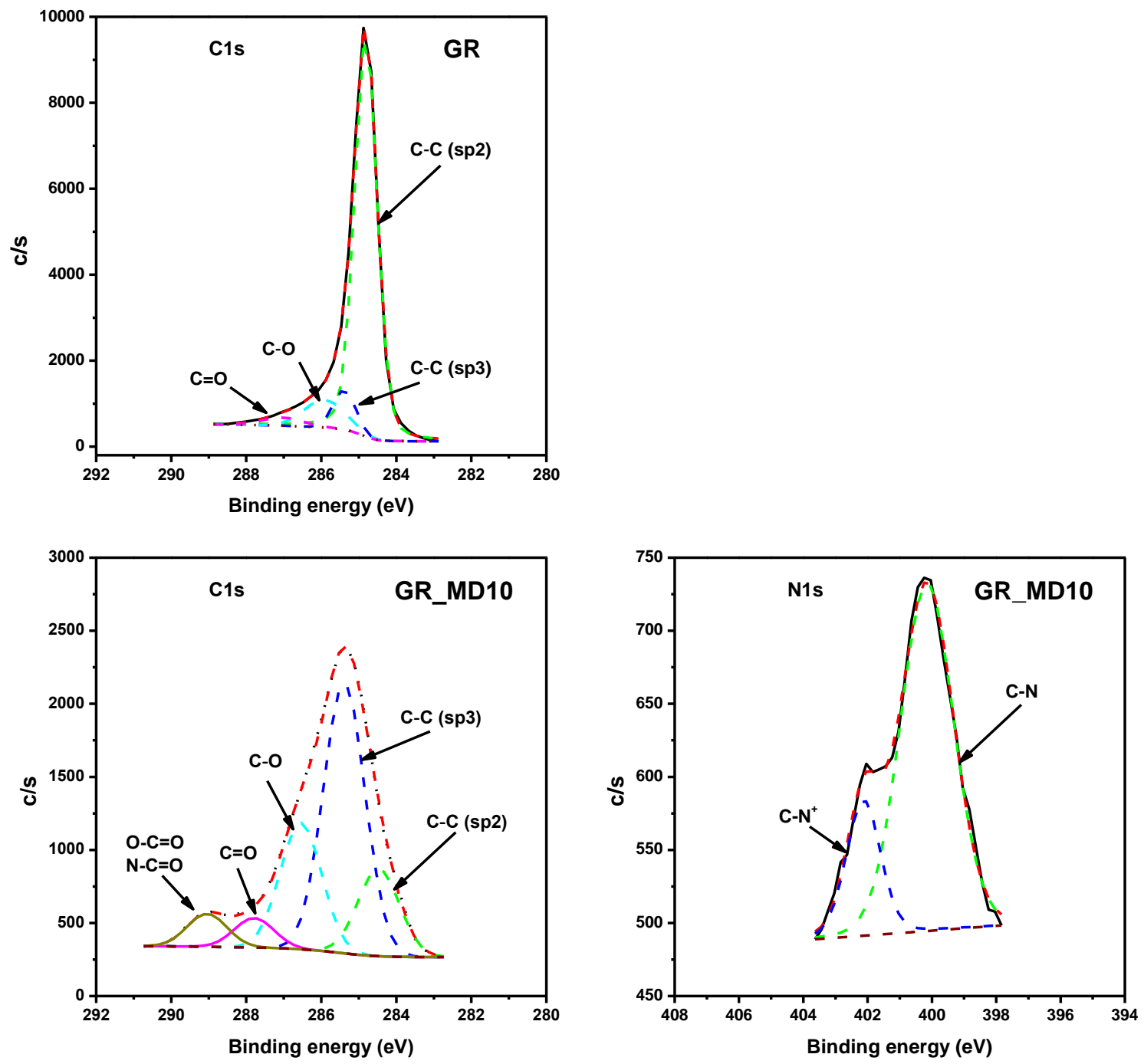

Figure 6. C1s and N1s XPS spectra of GO and GO_MD10. 

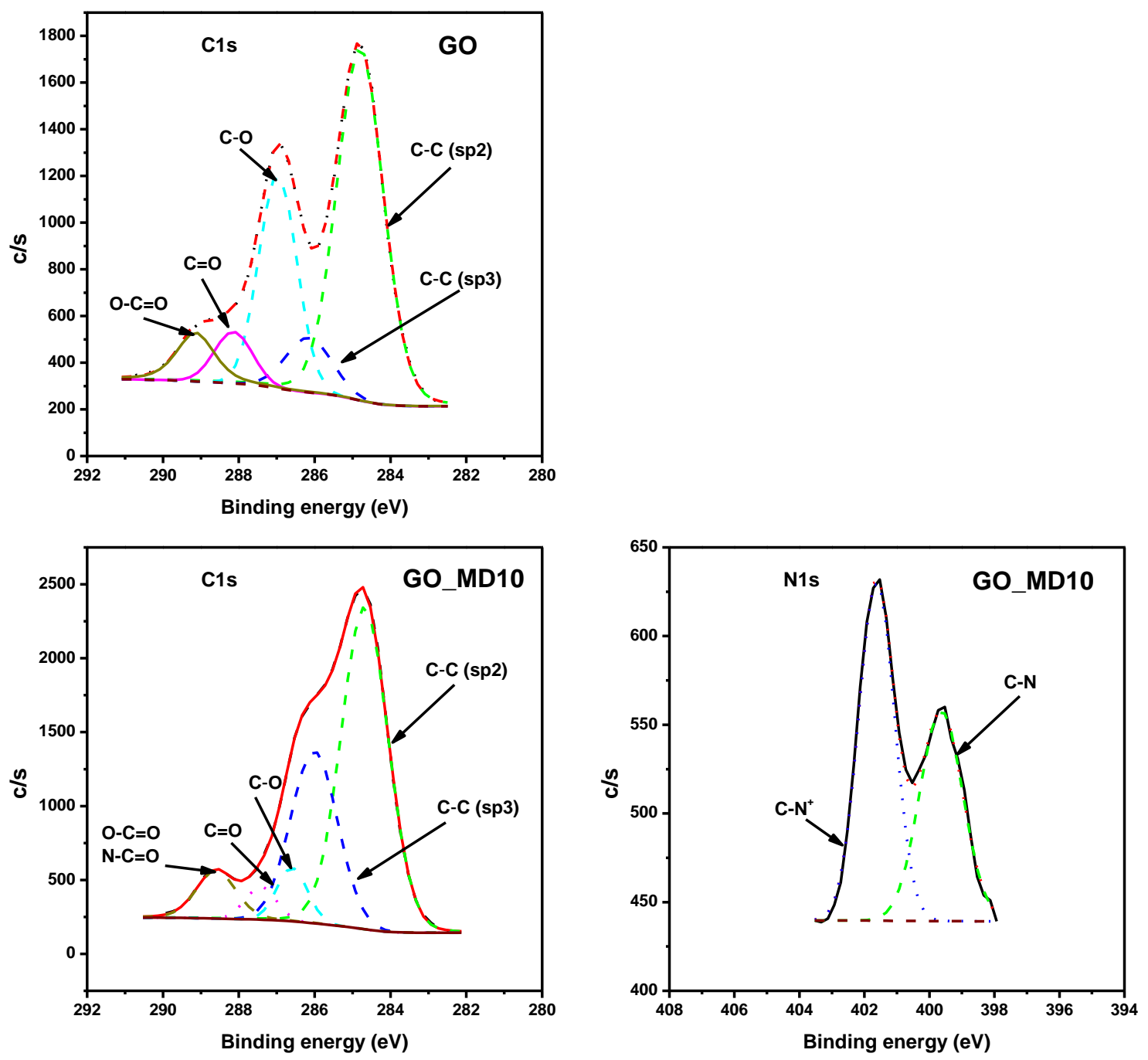

Figure 7. C1s and N1s XPS spectra of GR and GR_MD10.

All these facts, confirm the functionalization of GO and GR with the cationic polymer probably through both, electrostatic interactions and by $\pi$-stacking between the hexagonal cells of graphene and graphene oxide and the aromatic ring structure of dopamine [45,46].

On the other hand, the C1s XPS spectrum of GR exhibits a dominant presence of the $\mathrm{C}$ atoms in the $\mathrm{C}=\mathrm{C}\left(\mathrm{sp}^{2}\right)$ bonds of the graphenic structure $(284.81 \mathrm{eV})$, with a lower occurrence of $\mathrm{C}$ atoms in $\mathrm{C}-\mathrm{C}\left(\mathrm{sp}^{3}\right)$ bonds at $285.23 \mathrm{eV}$, which confirms the low impurities observed by Raman measurements. The $-\mathrm{C}-\mathrm{O}$ and $\mathrm{C}=\mathrm{O}$ groups are occurring with much lower intensities than in case of $\mathrm{GO}$ (285.91 and $287.03 \mathrm{eV}$, respectively), almost negligible. The $\mathrm{C} / \mathrm{O}$ ratio is approximately 1.1 for GO while is 60.7 for GR.

The C1s spectrum of GR_MD10 has similar profile than GO_MD10 but with lower proportion of carbonyl groups as expected. Besides, there is also an increment of intensity in the $\mathrm{C}-\mathrm{C}\left(\mathrm{sp}^{3}\right)$ peak due to the polymer attachment. In the N1s spectrum, GR_DM10 presents $\mathrm{O}=\mathrm{C}-\mathrm{N}$ and $\mathrm{C}-\mathrm{N}^{+}$groups, which newly confirm the functionalization of GR.

The $\zeta$ potential in water solutions was also measured to confirm this functionalization. The values are gathered in Table 2 and, as is noticeable, the values of quaternized polymer present high positive charge according to those previously obtained [33]. In contrast, GO and GR present negative values due to their preparation methods and their values are also in agreement to reported values $[47,48]$. The negative value of GR means that its flakes size is large $\left(>0.46 \mathrm{~mm}^{2}\right)$; since only the absolute value of zeta potential, which is more than $30 \mathrm{mV}$, can ensure its good dispersion stability [49]. 
Table 2. $\zeta$ potentials of the different materials.

\begin{tabular}{cc}
\hline Material & $\zeta$ Potential $(\mathbf{m V})$ \\
\hline MD10 & $71 \pm 5$ \\
\hline GO & $-36 \pm 3$ \\
GO_MD10 & $35 \pm 5$ \\
\hline GR & $-30 \pm 3$ \\
GR_MD10 & $61 \pm 4$ \\
\hline
\end{tabular}

The functionalization with MD10 makes the carbonaceous materials positively charged and also form stable dispersions. In the case of GO_MD10, this positive charge is lower than for GR_MD10, which could be explained by the stronger negative charge of GO in comparison with GR and the higher proportion of $-\mathrm{COO}^{-}$that could compensate the positive charge of polymer MD10 before the attachment by the catechol groups.

As mentioned before, the charges are also important in the antimicrobial response of materials. The antimicrobial behavior of the cationic MD10 polymer was previously eValuated and their minimal inhibitory concentration (MIC) values ranging from $8-64 \mu \mathrm{g} / \mathrm{mL}$ against the tested bacteria $[33,50]$. Having this in mind, the antimicrobial eValuation of carbon-based materials is performed by contact killing of material $(500 \mu \mathrm{g} / \mathrm{mL})$ and bacteria during $24 \mathrm{~h}$ under soft moving. Figure 8 shows the antibacterial ratio against Gram-positive (S. aureus and S. epidermidis) and Gram-negative (P. aeruginosa and E. coli) bacteria for GO and GR derivatives including also GO, respectively. It is noticeable that the activities of GO against bacteria is slightly improved with the incorporation of MD10 except against P. aeruginosa and S. aureus bacteria. Remarkably, hybrid GR_MD10 presents the best results of all, which can be explained by the higher positive charge of the system. It is important to note, that in the case of GR, it was not possible to obtain stable water dispersion during $24 \mathrm{~h}$ and then GR sheets did not kill the bacteria at the tested concentration. The incorporation of the cationic polymer significantly improves the water stability, also providing antimicrobial activity. Likewise, the graphene hybrid sample is also more effective against Gram-negative than Gram-positive bacteria. This could be explained by the difference on composition and thickness of the corresponding bacterial cell membranes.

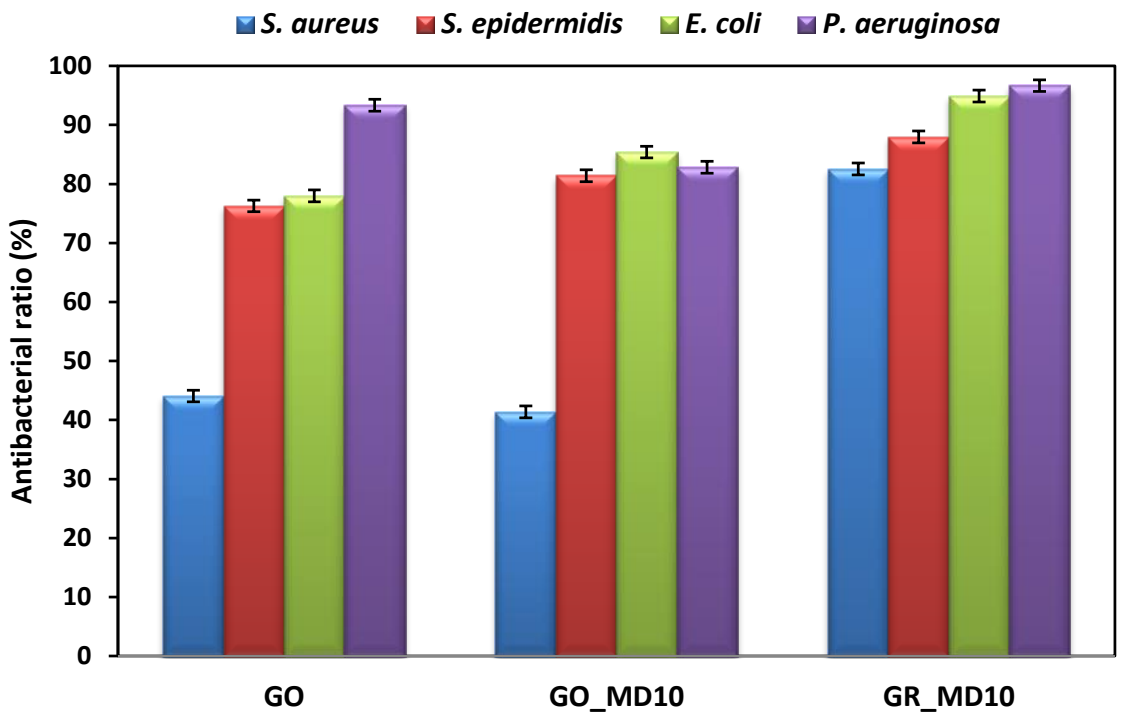

Figure 8. Antibacterial ratio of hybrid materials and GO against bacteria.

\section{Conclusions}

The successful functionalization of graphene oxide and graphene with the quaternized statistical copolymer P(MTA90-co-DOMA10), MD10, was confirmed by FTIR, Raman spectroscopy and XPS 
and the products were further eValuated as antibacterial materials. The structural characterization performed by FTIR confirmed the presence of $\mathrm{C}=\mathrm{O}$ groups (from MTA) in both hybrid GO_MD10 and GR_MD10 systems. The analysis of the Raman spectra confirmed the functionalization of GO with the cationic polymer through the presence of a new band corresponding to the $\mathrm{C}-\mathrm{O}-\mathrm{C}$ bonds from the ring of DOMA and the graphitic structure of GO, but inducing no changes in the GO structure. In the case of GR, the incorporation of the cationic polymer onto the GR sheets resulted in a structural modification, probably due to the intercalation of the cationic polymer between the graphitic layers and the subsequent formation of graphenic stacks with less number of layers. The functionalization of GR and GO by MD10 quaternized copolymer was also eVidenced by the significant change of superficial charge from negative to highly positive values determined by the potential zeta analysis. Moreover, due to the positive charge obtained with the attachment, the hybrid polymeric materials presented good antimicrobial activity against Gram-positive and Gram-negative bacteria, especially in the case of graphene, which activity in water solution is insignificant.

Author Contributions: Investigation, D.P., A.M.-B., K.Š., C.E.; A.C., M.P., K.L., and M.F.-G.; writing-original draft preparation, D.P., A.M.-B. and M.F.-G.; writing-review and editing, D.P., A.M.-B. and M.F.-G.; funding acquisition, D.P. and M.F.-G. All authors have read and agreed to the published version of the manuscript.

Funding: This work was funded by the MINECO (Project MAT2016-78437-R), the Agencia Estatal de Investigación (AEI, Spain) and Fondo Europeo de Desarrollo Regional (FEDER, EU) and by Ministry of Education of the Czech Republic through the SGS project SP2020/70.

Acknowledgments: C. Echeverria and A. Chiloeches also acknowledge MINECO for her IJCI-2015-26432 contract and his FPU fellowship FPU18/01776, respectively. Authors want to acknowledge the ICTP-CSIC people on the Service of Characterization and Technical Scientific Assistance for their support in the measurements.

Conflicts of Interest: The authors declare no conflict of interest.

\section{References}

1. Shi, L.; Chen, J.; Teng, L.; Wang, L.; Zhu, G.; Liu, S.; Luo, Z.; Shi, X.; Wang, Y.; Ren, L. The antibacterial applications of graphene and its derivatives. Small 2016, 12, 4165-4184. [CrossRef] [PubMed]

2. Zhu, J.; Wang, J.; Hou, J.; Zhang, Y.; Liu, J.; Van der Bruggen, B. Graphene-based antimicrobial polymeric membranes: A review. J. Mater. Chem. A 2017, 5, 6776-6793. [CrossRef]

3. Zou, X.; Zhang, L.; Wang, Z.; Luo, Y. Mechanisms of the antimicrobial activities of graphene materials. J. Am. Chem. Soc. 2016, 138, 2064-2077. [CrossRef] [PubMed]

4. Zhang, Z.; Zhang, J.; Zhang, B.; Tang, J. Mussel-inspired functionalization of graphene for synthesizing ag-polydopamine-graphenenanosheets as antibacterial materials. Nanoscale 2013, 5, 118-123. [CrossRef] [PubMed]

5. Tiraferri, A.; Vecitis, C.D.; Elimelech, M. Covalent binding of single-walled carbon nanotubes to polyamide membranes for antimicrobial surface properties. ACS Appl. Mater. Interfaces 2011, 3, 2869-2877. [CrossRef] [PubMed]

6. Santos, C.M.; Tria, M.C.; Vergara, R.A.; Ahmed, F.; Advincula, R.C.; Rodrigues, D.F. Antimicrobial graphene polymer (pvk-go) nanocomposite films. Chem. Commun. (Camb.) 2011, 47, 8892-8894. [CrossRef]

7. Santos, C.M.; Milagros Cui, K.; Ahmed, F.; Tria, M.C.R.; Vergara, R.A.M.V.; de Leon, A.C.; Advincula, R.C.; Rodrigues, D.F. Bactericidal and anticorrosion properties in pvk/mwnt nanocomposite coatings on stainless steel. Macromol. Mater. Eng. 2012, 297, 807-813. [CrossRef]

8. Pangilinan, K.D.; Santos, C.M.; Estillore, N.C.; Rodrigues, D.F.; Advincula, R.C. Temperature-responsiveness and antimicrobial properties of cnt-pnipam hybrid brush films. Macromol. Chem. Phys. 2013, 214, 464-469. [CrossRef]

9. Aslan, S.; Deneufchatel, M.; Hashmi, S.; Li, N.; Pfefferle, L.D.; Elimelech, M.; Pauthe, E.; Van Tassel, P.R. Carbon nanotube-based antimicrobial biomaterials formed via layer-by-layer assembly with polypeptides. J. Colloid Interface Sci. 2012, 388, 268-273. [CrossRef]

10. Mejias Carpio, I.E.; Santos, C.M.; Wei, X.; Rodrigues, D.F. Toxicity of a polymer-graphene oxide composite against bacterial planktonic cells, biofilms, and mammalian cells. Nanoscale 2012, 4, 4746-4756. [CrossRef] 
11. Hegab, H.M.; ElMekawy, A.; Zou, L.; Mulcahy, D.; Saint, C.P.; Ginic-Markovic, M. The controversial antibacterial activity of graphene-based materials. Carbon 2016, 105, 362-376. [CrossRef]

12. Placha, D.; Jampilek, J. Graphenic materials for biomedical applications. Nanomaterials 2019, 9, 1758. [CrossRef] [PubMed]

13. Pham, V.T.H.; Truong, V.K.; Quinn, M.D.J.; Notley, S.M.; Guo, Y.; Baulin, V.A.; Al Kobaisi, M.; Crawford, R.J.; Ivanova, E.P. Graphene induces formation of pores that kill spherical and rod-shaped bacteria. ACS Nano 2015, 9, 8458-8467. [CrossRef] [PubMed]

14. Sawangphruk, M.; Srimuk, P.; Chiochan, P.; Sangsri, T.; Siwayaprahm, P. Synthesis and antifungal activity of reduced graphene oxide nanosheets. Carbon 2012, 50, 5156-5161. [CrossRef]

15. Akhavan, O.; Ghaderi, E.; Esfandiar, A. Wrapping bacteria by graphene nanosheets for isolation from environment, reactivation by sonication, and inactivation by near-infrared irradiation. J. Phys. Chem. B 2011, 115, 6279-6288. [CrossRef]

16. Di Giulio, M.; Zappacosta, R.; Di Lodovico, S.; Di Campli, E.; Siani, G.; Fontana, A.; Cellini, L. Antimicrobial and antibiofilm efficacy of graphene oxide against chronic wound microorganisms. Antimicrob. Agents Chemother. 2018, 62, e00547-18. [CrossRef]

17. Hou, W.-C.; Lee, P.-L.; Chou, Y.-C.; Wang, Y.-S. Antibacterial property of graphene oxide: The role of phototransformation. Environ. Sci. Nano 2017, 4, 647-657. [CrossRef]

18. Romero, M.P.; Marangoni, V.S.; de Faria, C.G.; Leite, I.S.; Silva, C.; Maroneze, C.M.; Pereira-da-Silva, M.A.; Bagnato, V.S.; Inada, N.M. Graphene oxide mediated broad-spectrum antibacterial based on bimodal action of photodynamic and photothermal effects. Front. Microbiol. 2019, 10, 2995. [CrossRef]

19. Lim, H.N.; Huang, N.M.; Loo, C.H. Facile preparation of graphene-based chitosan films: Enhanced thermal, mechanical and antibacterial properties. J. Non Cryst. Solids 2012, 358, 525-530. [CrossRef]

20. Park, S.; Ruoff, R.S. Chemical methods for the production of graphenes. Nat. Nanotechnol. 2009, 4, $217-224$. [CrossRef]

21. Kumar, P.; Huo, P.; Zhang, R.; Liu, B. Antibacterial properties of graphene-based nanomaterials. Nanomaterials 2019, 9, 737. [CrossRef] [PubMed]

22. Zhang, P.; Wang, H.; Zhang, X.; Xu, W.; Li, Y.; Li, Q.; Wei, G.; Su, Z. Graphene film doped with silver nanoparticles: Self-assembly formation, structural characterizations, antibacterial ability, and biocompatibility. Biomater. Sci. 2015, 3, 852-860. [CrossRef] [PubMed]

23. Tian, T.; Shi, X.; Cheng, L.; Luo, Y.; Dong, Z.; Gong, H.; Xu, L.; Zhong, Z.; Peng, R.; Liu, Z. Graphene-based nanocomposite as an effective, multifunctional, and recyclable antibacterial agent. ACS Appl. Mater. Interfaces 2014, 6, 8542-8548. [CrossRef] [PubMed]

24. Cobos, M.; De-La-Pinta, I.; Quindos, G.; Fernandez, M.J.; Fernandez, M.D. Graphene oxide-silver nanoparticle nanohybrids: Synthesis, characterization, and antimicrobial properties. Nanomaterials 2020, 10, 376. [CrossRef]

25. Zhao, R.; Kong, W.; Sun, M.; Yang, Y.; Liu, W.; Lv, M.; Song, S.; Wang, L.; Song, H.; Hao, R. Highly stable graphene-based nanocomposite (GO-PEI-Ag) with broad-spectrum, long-term antimicrobial activity and antibiofilm effects. ACS Appl. Mater. Interfaces 2018, 10, 17617-17629. [CrossRef]

26. Raja, A.; Selvakumar, K.; Rajasekaran, P.; Arunpandian, M.; Ashokkumar, S.; Kaviyarasu, K.; Asath Bahadur, S.; Swaminathan, M. Visible active reduced graphene oxide loaded titania for photodecomposition of ciprofloxacin and its antibacterial activity. Colloids Surf. Physicochem. Eng. Asp. 2019, 564, 23-30. [CrossRef]

27. Hsueh, Y.H.; Hsieh, C.T.; Chiu, S.T.; Tsai, P.H.; Liu, C.Y.; Ke, W.J. Antibacterial property of composites of reduced graphene oxide with nano-silver and zinc oxide nanoparticles synthesized using a microwave-assisted approach. Int. J. Mol. Sci. 2019, 20, 5394. [CrossRef]

28. Archana, S.; Kumar, K.Y.; Jayanna, B.K.; Olivera, S.; Anand, A.; Prashanth, M.K.; Muralidhara, H.B. Versatile graphene oxide decorated by star shaped zinc oxide nanocomposites with superior adsorption capacity and antimicrobial activity. J. Sci. Adv. Mater. Devices 2018, 3, 167-174. [CrossRef]

29. Nguyen, H.N.; Nadres, E.T.; Alamani, B.G.; Rodrigues, D.F. Designing polymeric adhesives for antimicrobial materials: Poly(ethylene imine) polymer, graphene, graphene oxide and molybdenum trioxide - a biomimetic approach. J. Mater. Chem. B 2017, 5, 6616-6628. [CrossRef] 
30. Mazaheri, M.; Akhavan, O.; Simchi, A. Flexible bactericidal graphene oxide-chitosan layers for stem cell proliferation. Appl. Surf. Sci. 2014, 301, 456-462. [CrossRef]

31. Liu, T.; Liu, Y.; Liu, M.; Wang, Y.; He, W.; Shi, G.; Hu, X.; Zhan, R.; Luo, G.; Xing, M.; et al. Synthesis of graphene oxide-quaternary ammonium nanocomposite with synergistic antibacterial activity to promote infected wound healing. Burn. Trauma 2018, 6, 16. [CrossRef] [PubMed]

32. Tu, Q.; Tian, C.; Ma, T.; Pang, L.; Wang, J. Click synthesis of quaternized poly(dimethylaminoethyl methacrylate) functionalized graphene oxide with improved antibacterial and antifouling ability. Colloids Surf. B Biointerfaces 2016, 141, 196-205. [CrossRef] [PubMed]

33. Chiloeches, A.; Echeverría, C.; Cuervo-Rodríguez, R.; Plachà, D.; López-Fabal, F.; Fernández-García, M.; Muñoz-Bonilla, A. Adhesive antibacterial coatings based on copolymers bearing thiazolium cationic groups and catechol moieties as robust anchors. Prog. Org. Coat. 2019, 136, 105272. [CrossRef]

34. Hummers, W.S.; Offeman, R.E. Preparation of graphitic oxide. J. Am. Chem. Soc. 1958, 80, 1339. [CrossRef]

35. Guadagno, L.; Raimondo, M.; Vertuccio, L.; Mauro, M.; Guerra, G.; Lafdi, K.; De Vivo, B.; Lamberti, P.; Spinelli, G.; Tucci, V. Optimization of graphene-based materials outperforming host epoxy matrices. RSC Adv. 2015, 5, 36969-36978. [CrossRef]

36. Díez-Betriu, X.; Álvarez-García, S.; Botas, C.; Álvarez, P.; Sánchez-Marcos, J.; Prieto, C.; Menéndez, R.; de Andrés, A. Raman spectroscopy for the study of reduction mechanisms and optimization of conductivity in graphene oxide thin films. J. Mater. Chem. C 2013, 1, 6905. [CrossRef]

37. Kim, S.-G.; Park, O.-K.; Lee, J.H.; Ku, B.-C. Layer-by-layer assembled graphene oxide films and barrier properties of thermally reduced graphene oxide membranes. Carbon Lett. 2013, 14, 247-250. [CrossRef]

38. Vidano, R.P.; Fischbach, D.B.; Willis, L.J.; Loehr, T.M. Observation of raman band shifting with excitation wavelength for carbons and graphites. Solid State Commun. 1981, 39, 341-344. [CrossRef]

39. Hao, Y.; Wang, Y.; Wang, L.; Ni, Z.; Wang, Z.; Wang, R.; Koo, C.K.; Shen, Z.; Thong, J.T.L. Probing layer number and stacking order of few-layer graphene by raman spectroscopy. Small 2010, 6, 195-200. [CrossRef]

40. Malard, L.M.; Pimenta, M.A.; Dresselhaus, G.; Dresselhaus, M.S. Raman spectroscopy in graphene. Phys. Rep. 2009, 473, 51-87. [CrossRef]

41. Chiloeches, A.; Echeverría, C.; Fernández-García, M.; Muñoz-Bonilla, A. Influence of polymer composition and substrate on the performance of bioinspired coatings with antibacterial activity. Coatings 2019, 9, 733. [CrossRef]

42. Gurzęa, B.; Florczak, P.; Wiesner, M.; Kempiński, M.; Jurga, S.; Krawczyk, P. Graphene material prepared by thermal reduction of the electrochemically synthesized graphite oxide. RSC Adv. 2016, 6, 63058-63063. [CrossRef]

43. Thomas, H.R.; Phillips, D.J.; Wilson, N.R.; Gibson, M.I.; Rourke, J.P. One-step grafting of polymers to graphene oxide. Polym. Chem. 2015, 6, 8270-8274. [CrossRef] [PubMed]

44. Larciprete, R.; Fabris, S.; Sun, T.; Lacovig, P.; Baraldi, A.; Lizzit, S. Dual path mechanism in the thermal reduction of graphene oxide. J. Am. Chem. Soc. 2011, 133, 17315-17321. [CrossRef] [PubMed]

45. Faure, E.; Falentin-Daudré, C.; Jérôme, C.; Lyskawa, J.; Fournier, D.; Woisel, P.; Detrembleur, C. Catechols as versatile platforms in polymer chemistry. Prog. Polym. Sci. 2013, 38, 236-270. [CrossRef]

46. Kaminska, I.; Das, M.R.; Coffinier, Y.; Niedziolka-Jonsson, J.; Sobczak, J.; Woisel, P.; Lyskawa, J.; Opallo, M.; Boukherroub, R.; Szunerits, S. Reduction and functionalization of graphene oxide sheets using biomimetic dopamine derivatives in one step. ACS Appl. Mater. Interfaces 2012, 4, 1016-1020. [CrossRef]

47. Vallés, C.; Drummond, C.; Saadaoui, H.; Furtado, C.A.; He, M.; Roubeau, O.; Ortolani, L.; Monthioux, M.; Pénicaud, A. Solutions of negatively charged graphene sheets and ribbons. J. Am. Chem. Soc. 2008, 130, 15802-15804. [CrossRef]

48. Zhu, H.; Gao, L.; Jiang, X.; Liu, R.; Wei, Y.; Wang, Y.; Zhao, Y.; Chai, Z.; Gao, X. Positively charged graphene oxide nanoparticle: Precisely label the plasma membrane of live cell and sensitively monitor extracellular ph in situ. Chem. Commun. (Camb.) 2014, 50, 3695-3698. [CrossRef] 
49. Yi, M.; Shen, Z.; Liang, S.; Liu, L.; Zhang, X.; Ma, S. Water can stably disperse liquid-exfoliated graphene. Chem. Commun. (Camb.) 2013, 49, 11059-11061. [CrossRef]

50. Tejero, R.; López, D.; López-Fabal, F.; Gómez-Garcés, J.L.; Fernández-García, M. Antimicrobial polymethacrylates based on quaternized 1,3-thiazole and 1,2,3-triazole side-chain groups. Polym. Chem. 2015, 6, 3449-3459. [CrossRef]

(C) 2020 by the authors. Licensee MDPI, Basel, Switzerland. This article is an open access article distributed under the terms and conditions of the Creative Commons Attribution (CC BY) license (http://creativecommons.org/licenses/by/4.0/). 